\title{
Breve análise do rapto internacional de crianças na jurisprudência portuguesa
}

https://doi.org/10.21814/uminho.ed.30.5

\author{
Anabela Susana de Sousa Gonçalves \\ Professora Associada da Escola de Direito da \\ Universidade do Minho
}

\section{Proposta}

Estamos perante uma situação de rapto internacional de crianças quando há uma deslocação da criança para um país estrangeiro, ou retenção da criança num país estrangeiro, em violação de um direito de guarda conferido por decisão judicial, por atribuição de pleno direito ou por acordo de acordo com a lei da residência habitual da criança antes da deslocação ou retenção, desde que o direito de guarda estivesse a ser efetivamente exercido, ou devesse estar a ser, caso não tivesse ocorrido a deslocação ou retenção.

O rapto internacional de crianças tem a sua regulamentação jurídica em dois instrumentos que os tribunais têm de articular nas suas decisões: o Regulamento $n .^{\circ}$ 2201/2003 sobre a competência internacional e o reconhecimento de decisões em matéria matrimonial e de responsabilidade parental (Bruxelas II bis) e a Convenção de Haia, de 25 de outubro de 1980, sobre Aspetos Civis do Rapto Internacional de Menores (Convenção de Haia). A necessidade de conjugar estes dois regimes resulta do considerando 17 e no artigo $11^{\circ}$ do Regulamento. 0 art. $60^{\circ}$, al. e) estabelece, ainda, a precedência do Regulamento Bruxelas II bis sobre a Convenção de Haia nas relações entre os Estados-Membros. Isto significa que a Convenção continua a aplicar-se, mas que vê o seu regime completo pelo disposto no Regulamento quanto à deslocação ou retenção ilícitas de crianças ${ }^{1}$.

A definição de rapto internacional de crianças, referida supra, consta do art. $2^{\circ}$, n. $^{\circ} 11$ do Regulamento, coincidindo com a noção presente no art. $3^{\circ}$ da Convenção de Haia de 1980. Direito de guarda é definido no art. $2^{\circ}$, n. $^{\circ} 9$ do Regulamento, como os direitos referentes à assistência e cuidados da pessoa da criança, sendo um deles o direito de determinar a residência habitual da criança. Esta noção coincide com

1 Com mais informações sobre o âmbito de aplicação das fontes aplicáveis ao rapto internacional de crianças, v. GONÇALVES, Anabela Susana de Sousa - O caso Rinau e a deslocação ou retenção ilícitas de crianças. "Temas de Direito Internacional Privado e de processo Civil Internacional”. Porto: Librum Editora, 2019, pp. 75-102. 
aquela presente no art. $5^{\circ}$, al. a) da Convenção de Haia de 1980. A determinação do direito de guarda é feita de acordo com a lei da residência habitual da criança antes da deslocação.

O objetivo deste estudo será apresentar de forma necessariamente breve algumas tendências da jurisprudência portuguesa em relação ao rapto internacional de crianças, nomeadamente quanto ao conceito de rapto internacional de crianças, o procedimento urgente de regresso e as exceções que podem fundamentar uma decisão de retenção.

\section{O regresso célere da criança ao Estado da sua residência habitual}

As regras de competência internacional referentes à responsabilidade parental foram inspiradas no superior interesse da criança e, nesta medida, no princípio de proximidade, como se lê no considerando 12. A atribuição da competência ao tribunal mais próximo da criança concretiza-se no art. $8^{\circ}$, pela atribuição de competência aos tribunais do Estado-Membro onde reside da criança à data em que o processo é instaurado no tribunal. No momento de instauração do processo, o tribunal adquire competência e intervém até que haja alteração lícita da residência habitual da criança para outro Estado-Membro.

A regra geral quanto à deslocação ou retenção ilícitas está prevista no art. $10^{\circ}$ do Regulamento: os tribunais do Estado-Membro da residência habitual da criança antes da deslocação ilícita continuam a ser competentes após essa deslocação ilícita até que a criança disponha de outra residência habitual num país da UE, o que apenas acontece se estiverem reunidas as circunstâncias previstas nas alíneas daquela norma. Esta estabilidade que advém da manutenção da competência do tribunal da residência habitual de origem da criança permite a obtenção de uma decisão mais célere de regresso, caso se justifique, evitando disputas dilatórias em torno da jurisdição competente. Também se evita, desta forma, favorecer o progenitor que ilicitamente deslocou a criança para outro Estado-Membro, atribuindo competência a um tribunal que naquele momento lhe é mais próximo.

As regras previstas no Regulamento quanto à deslocação ou retenção ilícitas de criança têm um objetivo claro de estabelecer um procedimento célere que permita o regresso imediato da criança ao Estado da sua residência habitual. O mecanismo de regresso imediato da criança, previsto no regulamento, baseia-se num princípio de cooperação judiciária entre os tribunais e autoridades centrais dos Estados- Membros², e visa desencorajar a deslocação ilícita de crianças dentro da União, de forma a respeitar os interesses e vínculos afetivos das crianças. Em caso de

2 O Regulamento institui autoridades centrais, que têm várias funções e têm como objetivo geral o reforço da cooperação entre os Estados-Membros e melhorar a aplicação do regulamento Bruxelas II bis (art. 54 e $55^{\circ}$ ). Entre essas funções constam (art. $54 .^{\circ}$ e $55^{\circ}$ ), entre outras: favorecer o intercâmbio de informações sobre a legislação e procedimentos nacionais respetivos (art. 54. ${ }^{\circ}$ ); ou recolher e proceder ao intercâmbio de informações sobre a situação da criança, sobre qualquer procedimento em curso e sobre qualquer decisão proferida em relação à criança [art. 55, al. a)]; ou facilitar as comunicações entre os tribunais dos 
ocorrência destas situações pretende-se obter um regresso rápido da criança, não premiando o pai que raptou a criança com um processo longo e moroso e evitando agravar os danos ocorridos no desenvolvimento afetivo da criança.

Isto mesmo foi reconhecido pelo Tribunal da Relação do Porto, na decisão de 24 de setembro de 2020, onde se afirma que o rapto internacional da criança não é no superior interesse da criança, mas sim o seu regresso ao país de residência habitual ${ }^{3}$. Também no acórdão da Relação do Porto, de 12 de outubro de 2020, no caso de uma criança deslocada do Brasil para Portugal pela mãe, sem autorização do pai, foi decido que era no superior interesse da criança retornar rapidamente ao Brasil ${ }^{4}$. Encontramos outro exemplo, na decisão do Tribunal da Relação de Lisboa, de 20 de dezembro de 2017, que envolvia a retenção de uma criança em Portugal após umas férias, não tendo esta regressado à Suíça, como deveria.

Em todos os casos se discutiu a noção de rapto internacional da criança, tendo-se decidido, corretamente, que a questão de aferir se aquele pai que deslocou a criança para outro país, ou a reteve noutro país, tem o poder de decidir sozinho o local da residência habitual da criança é determinado de acordo com a lei da residência habitual da criança antes da deslocação ou da retenção.

\section{A decisão de regresso}

Perante uma deslocação ilícita da criança para outro Estado-Membro, o art. $11^{\circ}$ do regulamento Bruxelas II bis complementa o disposto na Convenção de Haia de 1980, quanto ao procedimento a adotar. Nesta situação, estabelece o art. $8^{\circ}$ da Convenção de Haia de 1980 que qualquer pessoa, instituição ou organismo pode reportar o rapto junto às autoridades competentes do Estado da residência habitual da criança (autoridade central) ou de outro Estado contratante da Convenção de Haia, pedindo assistência para garantir o regresso da criança, pedido este que deve ser acompanhado dos elementos previstos na segunda parte da norma. A autoridade central que foi informada daquele facto deve transmiti-lo à autoridade central do Estado contratante onde a criança se encontra (art. $9^{\circ}$ da Convenção de Haia de 1980), que deve tentar promover as medidas necessárias para o regresso voluntário da criança (art. $10^{\circ}$ da Convenção de Haia de 1980).

vários Estados-Membros [art. 55, al. c)]. Em Portugal, a autoridade central é a Direcção-Geral de Reinserção Social. As mesmas autoridades centrais existem na Convenção de Haia, com idênticas funções.

3 Tribunal da Relação do Porto, Processo 4033/19.5T8AVR-A.P1, de 24-09-2020, Relator Aristides Rodrigues de Almeida, [consultado em 2021-04-01]. Disponível em http://www.dgsi.pt/jtrp.nsf/56a6e7121 657f91e80257cda00381fdf/04d3e36347b03afe80258610004e6c80?OpenDocument\&Highlight=0,rapt o,internacional,de,crian\%C3\%A7as.

4 Tribunal da Relação do Porto, Processo 2220/19.5T8GDM.P1, de 12-10-2020, relator Mendes Coelho, [consultado em 2021-04-01]. Disponível em http://www.dgsi.pt/jtrp.nsf/56a6e7121657f91e80257cda0 0381fdf/bf89672d2eb342c080258632004d73bd?OpenDocument\&Highlight=0, rapto,internacional,de,c rian\%C3\%A7as. 
Umas das formas de conseguir o regresso voluntário da criança é através do recurso à mediação. Em Portugal, o art. $24^{\circ}$ do Regime Geral do Processo Tutelar Cível estabelece que o juiz pode em qualquer fase do processo determinar a intervenção de serviços públicos ou privados de mediação, que homologará o acordo se satisfizer o interesse da criança, e permite satisfazer aquela determinação da Convenção de Haia.

O art. $11^{\circ}$ da Convenção de Haia de 1980 impõe ainda às autoridades judiciais ou administrativas dos Estados contratantes a obrigação de adotar procedimentos de urgência para o regresso da criança. Em caso de deslocação ou de retenção ilícitas de criança e se tiver decorrido menos de um ano entre a data da deslocação ou da retenção ilícitas e o início do processo perante a autoridade judicial ou administrativa do Estado Contratante onde a criança se encontra, aquela autoridade deve ordenar o regresso imediato da criança $\left(\right.$ art. $\left.12^{\circ}, \S 1\right)$. Da mesma forma, caso já tenha decorrido este prazo de um ano, a referida autoridade judicial ou administrativa deve ordenar o regresso da criança. Todavia, neste último caso, a Convenção permite a emissão de uma decisão de retenção da criança se for provado que a criança já está integrada no seu novo ambiente (art. $\left.12^{\circ}, \S 2\right)$.

O art. $11^{\circ}$ do Regulamento Bruxelas II bis, que é aplicável quando o titular do direito de guarda pede às autoridades competentes de outro Estado-Membro uma decisão de regresso de uma criança ilicitamente retida ou deslocada nesse Estado com base na Convenção de Haia de 1980, reitera a ideia do procedimento urgente, estabelecendo no seu n. ${ }^{\circ} 3$, que o tribunal onde foi apresentado o pedido de regresso da criança deve utilizar o procedimento mais expedito possível de acordo com a sua legislação nacional, devendo pronunciar-se no prazo máximo de seis semanas a contar da apresentação do pedido (art. $11 .^{\circ}$, n. $\left.^{\circ} 3\right)^{5}$. Este é um prazo relativamente curto, pensado porque as crianças têm um tempo de maturidade diferente dos adultos: basta pensar na evolução que uma criança de um ano de idade pode ter no espaço de tempo de um ano, em que desenvolve as suas capacidades motoras, linguísticas e cognitivas. Deste pedido deve resultar uma decisão de regresso da criança ao país da residência habitual de origem, podendo ainda em circunstâncias específicas resultar uma decisão de retenção ${ }^{6}$.

O procedimento a adotar por cada Estado deve ser urgente, célere e simplificado. Em Portugal, olhando para o Regime Geral do Processo Tutelar Cível, que estabelece o regime processual aplicável à regulação do exercício das responsabilidades parentais e questões conexas, verificamos que não existe uma forma especial de processo

5 Exceto em circunstâncias extraordinárias que impeçam o cumprimento deste prazo, que poderão consistir, por exemplo, na dificuldade de encontrar a criança. O Regulamento não tem uma sanção para o não cumprimento do prazo em causa, todavia, poderemos ponderar nestes casos a responsabilidade civil do Estado não cumpridor. Com esta opinião, PATAUT, E. - Art. 11. In Brussels // bis Regulation (ed. U. Magnus/P. Mankowski). Munich: Sellier European Law Publishers, 2012, p. 135.

6 Para mais pormenores, v. Tribunal da Relação do Lisboa, Processo3654/18.8T8CSC.L1-6, de 09-01-2020, relator Ana Paula Albarran Carvalho, [consultado em 2021-04-01]. Disponível em http://www. dgsi.pt/jtrl.nsf/33182fc732316039802565fa00497eec/d327d05dc119cbcd802584ef005d718d?OpenDo cument\&Highlight=0,rapto,internacional,de,crian\%C3\%A7as. 
tutelar cível para as ações de regresso e, por isso, os tribunais têm usado a providência tutelar cível comum, prevista no art. $67^{\circ}$ do Regime Geral do Processo Tutelar Cível, que permite que o tribunal possa ordenar livremente as diligências que repute necessárias antes de proferir a decisão final. Isto dá uma maior discricionariedade ao juiz na condução do processo, permitindo-lhe dar ao processo uma maior celeridade, o que tem uma vertente positiva, mas esta margem ampla dada ao juiz também tem sido alvo de críticas 7 . Por força do art. $13^{\circ}$ do Regime Geral do Processo Tutelar Cível, sendo este um processo de jurisdição voluntária, urgente, corre durante as férias judiciais, e as sentenças são proferidas no prazo de 15 dias [art. $986^{\circ}$, n. ${ }^{\circ} 3$, do Código de Processo Civil (CPC)].

As especificidades e as vantagens deste processo de jurisdição voluntária resultam de algumas decisões, como por exemplo da decisão do Tribunal da Relação de Lisboa, de 9 de janeiro de 2020. Por um lado, o tribunal tem ampla iniciativa probatória, não estando dependente dos factos alegados pelas partes, admitindo as provas que considerar necessárias (art. $986^{\circ}$, n. $^{\circ} 2$, do CPC). Além disso, nos termos do art. $987^{\circ}$ do CPC, o tribunal não está sujeito a critérios de legalidade estrita, devendo tomar em cada caso a solução que julgue mais conveniente e oportuna. No caso concreto, o requerido pediu a inquirição de dez testemunhas por videoconferência, na Arménia e na Rússia, a realização de uma perícia e a apresentação de documentos pela contraparte. $O$ Tribunal, de acordo com os critérios de conveniência e oportunidade permitidos pela jurisdição voluntária, indeferiu os referidos meios de prova com base na desnecessidade dos mesmos, ainda que tenha existido a audição do requerido, garantindo-se o exercício do contraditório. No Regime Geral do Processo Tutelar Cível, o princípio do contraditório e o direito de contraditório das partes está salvaguardado no art. $25^{\circ}$.

\section{A decisão de retenção}

0 regresso da criança pode ser recusado com base nos fundamentos previstos no art. $13^{\circ}$ da Convenção de Haia de 1980 (decisão de retenção). De notar, que o tribunal do rapto não tem competência para apreciar as questões de responsabilidade parental, porque para essas quem tem competência é o tribunal da residência habitual da criança. Assim foi decidido, corretamente, na Tribunal da Relação de Coimbra de 18 de fevereiro de $2020^{8}$ e na decisão do Tribunal da Relação de Guimarães, de 6 de junho de $2019^{9}$.

7 V. FIALHO, António José - Contributo para um regime processual das ações de regresso das crianças ilicitamente deslocadas ou retidas (CH 1980). “Julgar Online”, maio 2019, pp. 1-48.

8 Tribunal da Relação de Coimbra, Processo 2278/19.7T8ACB.C1, de 18-02-2020, Relator Vítor Amaral, [consultado em 2021-04-01]. Disponível em http://www.dgsi.pt/jtrc.nsf/c3fb530030ea1c61802568d90 05cd5bb/29c867e4fac377678025858b0052b163?OpenDocument\&Highlight=0, rapto, internacional,de, crian\%C3\%A7as.

9 Tribunal da Relação de Guimarães, Processo 4864/18.3T8GMR-B.G, de 06-06-2019, Relator José Amaral, [consultado em 2021-04-01]. Disponível em http://www.dgsi.pt/jtrg.nsf/86c25a698e4e7cb780257 9ec004d3832/d915c51e0afb08f78025842a0031a5fd?OpenDocument\&Highlight=0, rapto, internacional ,de,crian\%C3\%A7as. 
Os motivos que podem fundamentar uma decisão de recusa estão previstos no art. $1^{\circ}$ da Convenção de Haia. Não nos podendo debruçar sobre todos, ficaremos apenas por aquele que é dos mais utilizados para fundamentar uma decisão de retenção ${ }^{10}$.

De acordo com a al. b) do art. $13^{\circ}$ da Convenção de Haia, pode constituir fundamento de uma decisão de retenção o facto de o regresso representar um risco grave para a saúde física ou psíquica da criança ou colocar a criança numa situação intolerável. Para fazer este juízo, as autoridades administrativas ou competentes devem ter em conta a situação social da criança a partir de informações fornecidas pela autoridade central ou outra autoridade competente do Estado da residência habitual da criança (art. $13^{\circ}$, último parágrafo da Convenção de Haia). Todavia, o art. 13ㄹ, al. b) da Convenção de Haia não pode ser o fundamento da recusa do regresso, se for provado que foram tomadas as medidas concretas adequadas para garantir a proteção da criança após esse regresso, de acordo com o estabelecido no art. $11 .^{\circ}$, n. $^{\circ} 4$ do regulamento Bruxelas II bis. ${ }^{11}$ Assim, o Regulamento restringe o alcance do art. $13^{\circ}$, al. b) da Convenção de Haia de 1980, limitando-se as situações de decisões de não retorno com base naquele fundamento. Note-se que disposto no art. $13 .{ }^{\circ}$, al b), da Convenção de Haia deve ter uma interpretação restritiva, porque as decisões de retenção são consideradas uma exceção ao regime de regresso da criança que a Convenção tenta implementar e que resultam de um compromisso frágil ${ }^{12}$ entre os Estados contratantes.

De salientar neste âmbito, a decisão do Tribunal da Relação do Porto, de 24 de setembro de 2020, em que a criança foi deslocada pela mãe da Venezuela para o Porto ${ }^{13}$. Neste caso o Tribunal ponderou o risco de exposição a perigo físico, psíquico e colocação da criança numa situação intolerável, tendo ponderado que «(...) indispensável é (...) haja um risco real, efetivo, de verificação daqueles perigos, independentemente da dimensão destes, sendo certo que será situação intolerável toda aquela que razoavelmente não se possa esperar que a criança deva vivenciar» ${ }^{14}$. É de assinalar que neste caso era invocado, entre outros, que a situação de pandemia poria em causa a saúde da criança em caso de regresso à Venezuela e também se alegava que as dificuldades da viagem colocariam em risco a criança. Ora, decidiu o Tribunal

10 Sobre os motivos de recusa, v. GONÇALVES, Anabela Susana de Sousa - O caso Rinau e a deslocação ou retenção ilícitas de crianças. Cit., pp. 75-102.

11 Reconhecendo a dificuldade do juiz do processo em aferir se foram adotadas medidas adequadas de proteção no Estado-Membro de origem, sublinha a Comissão Europeia, o papel determinante de assistência que podem desempenhar as autoridades centrais do Estado de origem: Guia prático para a aplicação do novo Regulamento Bruxelas II-A. Bélgica 2015 [consultado em 2021-04-01], p. 37. Disponível em https://www.google.com/url?sa=t\&rct=j\&q=\&esrc=s\&source=web\&cd=\&ved=2ahUKEwi2va3Z hZ_xAhVSMewKHdATC9wQFjAAegQIAxAD\&url=https\%3A\%2F\%2Fe-justice.europa.eu\%2FfileDownload. do\%3Fid\%3D488478ee-a528-4609-8169-1db80942fb4b\&usg=AOvVaw2d5OGKzMA2ro2hgCYT-_R3.

12 Como se pode ler no relatório explicativo da convenção: Pérez-Vera, Elisa - Explanatory Report on the 1980 HCCH Child Abduction Convention, Haya: Bureau Permanent de Conférence, 1982, p. 49.

13 Tribunal da Relação do Porto, Processo 4033/19.5T8AVR-A.P1, de 24-09-2020, Relator Aristides Rodrigues de Almeida, [consultado em 2021-04-01]. Disponível em http://www.dgsi.pt/jtrp.nsf/56a6e7121 657f91e80257cda00381fdf/04d3e36347b03afe80258610004e6c80?OpenDocument\&Highlight=0,rapt o,internacional,de,crian\%C3\%A7as

14 Ibid. 
que a situação pandémica existia em Portugal e na Venezuela e que não era possível determinar em qual país a criança estaria em maior risco de contrair a doença e que a execução da ordem de regresso seria feita quando estivessem assegurados os cuidados sanitários indispensáveis (como a autorização de voos diretos para a Venezuela pelas autoridades públicas), não podendo as dificuldades de viagem constituir argumento para impedir esse regresso ${ }^{15}$.

Outro exemplo é a decisão do Tribunal da Relação do Porto, de 8 de março de 2019, em que uma criança de 4 anos foi deslocada do Reino Unido para Portugal. No caso foi considerado, e bem na nossa opinião, que a situação integrava o art. $13^{\circ}$, al. b), da Convenção de Haia, devido à prova de episódios de violência doméstica que envolviam o pai em relação à mãe, certificados pelas autoridades inglesas e que constavam num relatório da segurança social ${ }^{16}$. A exposição a situações de violência doméstica sobre a mãe necessariamente tem efeitos sobre a criança. A segunda parte da fundamentação deste Tribunal é que nos parece mais duvidosa. Em primeiro lugar, o argumento do temor de perseguição criminal por parte da mãe, que o próprio Tribunal considera excessivo ${ }^{17}$. Por um lado, o tribunal português pode entrar em contacto com as autoridades do Reino Unido para esclarecer esta questão e não ficar por simples suposições, usando para esse efeito as autoridades centrais, previstas na Convenção de Haia e no Regulamento Bruxelas II bis (que se aplicava à data). Por outro lado, o regime da Convenção de Haia e do Regulamento não existe para proteger o pai raptor e os fundamentos de retenção não devem ser usados para o efeito. Em segundo lugar, o Tribunal considera que, devido ao Brexit, regressando ao Reino Unido, a mãe terá dificuldade em estabelecer a sua vida profissional e a criança ficará exposta ao clima de conflitualidade existente entre os pais ${ }^{18}$. A primeira parte deste argumento foca-se mais na mãe do que na criança e não se percebe como o Tribunal infere que a mãe não conseguirá estabelecer a sua vida profissional do Reino Unido. Além disso, é importante assinalar que, mesmo não regressando ao Reino Unido, a criança tem direito a ter contactos regulares com o pai e, se o pai e a mãe insistirem em ter uma relação de conflitualidade, a criança vai estar sujeita a esse clima. Cabe aos pais, a ambos, alterarem isso, se necessário com auxílio do Tribunal e outras entidades públicas de proteção da criança.

\section{Conclusão}

O objetivo deste breve estudo foi apresentar alguma jurisprudência portuguesa relativa ao rapto internacional de crianças. Em relação ao conceito de rapto, verifica-se uma tendência em considerar que o rapto internacional não é no superior interesse

\footnotetext{
15 Ibid.

16 Tribunal da Relação do Porto, Processo 3484/16.1T8STS-A.P3, de 08-03-2019, Relator Manuel Domingos Fernandes, [consultado em 2021-04-01]. Disponível em http://www.dgsi.pt/jtrp.nsf/56a6e7121 657f91e80257cda00381fdf/a259d07da65a450a802583d700547747?OpenDocument\&Highlight=0,rap to,internacional,de,crian\%C3\%A7as

17 Ibid.

18 Ibid.
} 
da criança e que esta deve regressar rapidamente ao seu país de residência habitual. Há também a adoção de um processo de regresso urgente, pela utilização da providência tutelar cível comum, prevista no art. $67^{\circ}$ do Regime Geral do Processo Tutelar Cível, que dá uma maior discricionariedade ao juiz na condução do processo, permitindo-lhe imprimir uma maior celeridade. Por fim, analisamos duas decisões, em sentido oposto, relativas à al. b) do art. $13^{\circ}$ da Convenção de Haia, que pode fundamentar uma decisão de retenção. Estas decisões permitem-nos concretizar o que deve ser entendido como um risco grave para a saúde física ou psíquica da criança ou colocar a criança numa situação intolerável. Muitas outras decisões ficaram por analisar, o que nos dá um motivo para voltar a esta temática no futuro. 